\title{
ELEIÇÕES MUNICIPAIS: AS DETERMINANTES DO VOTO NA ELEIÇÃO DE 2008 EM SÃO PAULO ${ }^{1}$
}

Patrícia Alves da Cruz ${ }^{2}$

\section{INTRODUÇÃO}

O comportamento eleitoral tem sido uma das preocupações mais antigas da ciência política, identificar e analisar as determinantes que têm maior impacto na decisão do voto. Dessa forma, a eleição municipal é o "lócus" do processo eleitoral, momento no qual é possível perceber as particularidades do voto e as variáveis que tem maior influência para o resultado final do pleito, partindo do contexto socioeconômico e de fatores conjunturais.

A análise de disputas municipais atenta para a importância de estudos locais. Sendo que a justificativa para análises micro é apresentada por Trounstine (apud VEIGA; NEVES; SANTOS; 2010) a partir dos seguintes aspectos: primeiro, o nível local é fonte de numerosos resultados políticos importantes para as diferentes esferas de decisão; segundo, os resultados da análise podem trazer novos desafios e avanços metodológicos; e por fim, a análise eleitoral á nível municipal pode ampliar e diversificar o nicho de problemas e questões que as pesquisa a partir de contextos mais abrangentes, como eleições presidenciais não podem oferecer.

Além das razões já expostas por Troustine, a análise do cenário político local é importante porque apresenta uma nova dinâmica e fatores diferenciados na relação candidato e eleitor tais como: a

\footnotetext{
${ }^{1}$ Uma versão prévia desse artigo foi apresentado no IV Congresso Latino Americano de Opinião Pública da Wapor, Belo Horizonte, Brasil, 04-06 de maio de 2011.

2 Mestranda em Ciência Política, Programa de Pós Graduação da Universidade Federal Do Paraná UFPR. e-mail: patialves1@gmail.com
} 
presença de oligarquias, coronelismo, relações de amizade e troca de favores e, além das razões anteriormente descritas, as eleições municipais evidenciam características do contexto municipal que não são perceptíveis nas eleições presidenciais.

Os principais estudos realizados no Brasil sobre os determinantes do voto em eleições municipais foram produzidos na década de 1970, quando o regime político brasileiro era bipartidário. As mudanças ocorridas com o processo de redemocratização modificaram o perfil do eleitorado brasileiro. De acordo com Telles (2008), o eleitor tornou-se mais experiente em participação eleitoral, mais escolarizado e mais "velho", e com maior acesso às informações.

Telles (2008) argumenta que é importante verificar a lógica do eleitor no período pós-redemocratização, se essa lógica ainda segue baseada em clivagens econômicas e sociais. Outra variável que é válida para analisar o comportamento do eleitor em esferas municipais é a racionalidade do eleitor, por contextos microssociais, isto é, de que forma a racionalidade do eleitor pode estar relacionada aos aspectos da política local.

A partir de 1988 com o processo de redemocratização, dois elementos tiveram impacto no cenário político eleitoral. Primeiro, foi a permissão para que as eleições em municípios com mais 200 mil eleitores fosse realizada em dois turnos. E mais tarde, em 2007, com a aprovação da Emenda Constitucional n 16 que permitiria a reeleição. Com a inserção da reeleição na disputa eleitoral, tem-se um novo fator para a análise: a satisfação com a administração, sendo este, um argumento importante para a continuidade do governo. Sendo assim, vários cientistas atentaram para a importância das variáveis satisfacionistas como determinante para o direcionamento do voto.

Em relação à análise da variável satisfacionista destacam-se os seguintes trabalhos sobre a satisfação com o governo: Anastácia 
(2000), Soares (2000), Silveira (2002), Carreirão (2008), Veiga, Neves e Santos (2010) entre outros.

Como forma de ampliar as análises sobre as eleições municipais, a proposta deste artigo é estudar a eleição de 2008 no município de São Paulo a partir da análise do desempenho dos candidatos Gilberto Kassab (DEM) - candidato à reeleição - e Marta Suplicy (PT) ex - prefeita do município em 2000. Completam a lista de candidatos à prefeitura Geraldo Alckim (PSDB), ex-governador do Estado, Paulo Maluf (PP), ex-prefeito por duas vezes, Anaí Caproni (PCO), Ciro (PTC), Edmilson Costa (PCB), Ivan Valente (PSOL), Levy Fidelix (PRTB), Ruy Branco (PMN) e Soninha (PPS) - políticos já conhecidos do eleitorado do estado.

Para está análise utilizaremos o banco de dados da eleição municipal de 2008, gentilmente cedido pelo Instituto Brasileiro de Opinião Pública e Estatística - IBOPE³.

Com base na literatura sobre o tema, o objetivo deste trabalho é analisar a intenção de voto a partir de variáveis como sexo, escolaridade, faixa etária e renda familiar, além das variáveis satisfacionistas.

Considerando o objetivo proposto, o artigo está organizado em três partes, além da introdução: no primeiro momento apresentaremos uma discussão sobre as teorias do comportamento eleitoral, procurando identificar a teoria que melhor se adapta à explicação do artigo; em seguida, faremos a exposição dos dados obtidos por meio dos testes estatísticos; e, por fim, uma conclusão sobre o perfil das intenções de voto do eleitorado em São Paulo nas eleições municipais de 2008.

\footnotetext{
${ }^{3}$ A autora agradece a Diretora do Ibope Márcia Cavallari por ter liberado o acesso ao banco de dados da eleição de 2008 .
} 


\section{REVISÃO DA LITERATURA}

Dentre as principais correntes explicativas para a decisão do voto, destacam-se a abordagem sociológica, a teoria psicológica ou psicossociologica e a teoria da escolha racional. Entre as abordagens descritas, daremos ênfase à discussão entre a teoria sociológica e a teoria da escolha racional, em razão do contexto no qual a análise está focada.

\subsection{TEORIA SOCIOLÓGICA}

A abordagem sociológica, pertencente à sociologia política, é conhecida como sociologia eleitoral. A teoria sociológica teve início a partir dos autores da Escola de Colúmbia em 1940. Dentre os principais clássicos da teoria podemos citar as seguintes obras: The People's Choice (1944) e Voting: a study of Opinion Formation in Presidential Campaign, (1966).

A discussão da obra desses autores está centrada na premissa de que os fatores explicativos do voto dizem respeito ao contexto social e interpessoal que os indivíduos estão inseridos. Essa abordagem procura conhecer as incidências dos processos socioeconômicos e culturais na conduta dos indivíduos. O pressuposto da teoria é que os eleitores em condições socioeconômicas semelhantes tendem a um comportamento político similar, logo que as condutas políticas derivam de posições estruturais ou dos chamados "coletivos sociais"

A principal conclusão dos autores "The people's choice" (1944) foi que existe uma predisposição inicial ao voto, que está relacionada à interação com o grupo social. O autor encontrou relação entre três aspectos sociais: o status sócio econômico, a religião e o local de residência dos eleitores. O eleitor sofre uma "cross pressure" (pressão cruzada) do grupo social na decisão do voto.

Nesse sentido, a sociologia política procura compreender o voto como um fenômeno adjacente ao contexto sócio-cultural do indivíduo. 
Nesse sentido, de acordo com Lipset (1967), para compreender o voto de um jovem ou de um idoso é necessário conhecer seu contexto social e político; onde esses eleitores vivem e como vivem neste contexto.

Como uma corrente explicativa derivada da perspectiva sociológica, as análises marxistas enfatizam a importância de fatores econômicos para o comportamento político dos indivíduos. De acordo com Figueiredo (2008, p. 62), “A tradição marxista parte da premissa de que a fonte da identidade política está na posição de classe dos indivíduos, funcionalmente definida." Não existe classe social, politicamente, se seus membros não tiverem consciência de classe, isto é, se os indivíduos não compartilharem dos mesmos princípios.

Essa abordagem foi utilizada por diversos trabalhos empíricos dentre os quais podemos destacar a síntese elaborada por Lipset (1967) sobre o perfil dos indivíduos quanto à intensidade da participação eleitoral. Soares (1974) destaca a importância tanto das características socioeconômicas como das bases classistas para 0 direcionamento que o eleitor dará ao voto.

[...] a escolha de um candidato não é um fenômeno abstrato abstratamente individual, desvinculado de toda a relação social: tanto de preferência partidária quanto a percepção das qualidades dos candidatos estão inseridas numa estrutura supra-individual cuja as bases sócio-econômicas em geral, e de classe em particular, são fundamentais na determinação do comportamento dos indivíduos (SOARES, 1974, p. 215).

Sendo assim, na medida em que a identificação com a classe diminui, aumenta a propensão dos indivíduos agirem de acordo com outros grupos, que não as classes sociais que pertencem.

[...] os operários vêem a sociedade como sendo composta de indivíduos e vêem a si próprios como membros da coletividade distinta de classe; comportam-se politicamente com base em afinidades 
religiosas, étnicas regionais ou outras. Tornam-se católicos, sulistas, francófonos ou simplesmente, “cidadãos" (PRZEWORSKI, 1989, p. 43).

Assim, pressupõe-se que os eleitores que trabalham, estudam e compartilham o mesmo ambiente, possuam as mesmas percepções políticas. As condições vivenciadas pelos indivíduos formam as atitudes políticas.

Partindo do princípio que a decisão do voto é resultante do contexto social e político, Figueiredo (2008) equaciona a decisão do voto da seguinte forma: "a direção do voto depende da natureza das relações políticas e sociais que os indivíduos estão envolvidos".

A hipótese geral que orienta esse tipo de estudo é que processos sociais amplos, como o avanço do capitalismo, são acompanhados por mudanças estruturais importantes, como a industrialização e a urbanização, que possibilitam a manifestação das clivagens sociais no apoio de camadas do eleitorado - classes ou estratos diferentes - a determinados partidos e candidatos (CASTRO, 1994).

\subsection{A TEORIA DA ESCOLHA RACIONAL}

A teoria da escolha racional tem como precursor Anthony Downs e sua obra "Uma teoria econômica da democracia" (1999). Essa obra foi precursora por ter construído uma modelo de análise, sob o viés racionalista, para o estudo das democracias eleitorais, sendo o modelo de indivíduo aquele racional e maximizador.

Em termos explicativos, a teoria da escolha racional parte da substituição do "homo sociologius" pelo "homo economicus". Essa é uma construção analítica que se preocupa em entender o comportamento humano a partir de adesões sociais, da consciência coletiva, do papel social e dos hábitos, enfim das predisposições internas que delimitam o comportamento dos indivíduos. 
A partir da definição de Downs, podemos presumir que o "homo economicus" é representado pelo indivíduo que maximiza seus interesses e demonstra um comportamento a partir do qual a premissa básica é adequar os meios aos fins pretendidos. Em relação ao comportamento eleitoral e aos fatores determinantes para o voto, podemos pressupor que direciona seu voto racionalmente tendo em vista a opção que the seja mais benéfica, tanto em ganhos econômicos como outros benefícios.

A teoria da escolha racional é baseada na teoria weberiana da ação social com relação a fins ${ }^{4}$, cujo objetivo desse agente econômico e social é maximizar seus ganhos. Apesar da teoria da escolha racional possuir aspectos econômicos, ela não é utilizada apenas para compreender os ganhos econômicos, "a maximização de interesses" em outras esferas como na decisão do voto e a participação em grupos de interesse, além do retorno econômico os benefícios podem ser traduzidos em prestígio, reconhecimento cultural e científico, entre outros argumentos além do econômico. Esse comportamento parte de uma conduta egoísta/altruísta, na qual faz parte do comportamento do indivíduo maximizar seus objetivos, "como ator social".

A participação na democracia, através do processo eleitoral (ato de votar) pode ser analisada a partir do comportamento maximizador. O eleitor é um ator racional e maximiza sua conduta, dessa maneira, destacam-se os seguintes cálculos: a importância do voto individual é ínfimo/nulo e o custo da ação de votar supera o valor do voto. De acordo com Downs:

Os benefícios que os eleitores consideram, ao tomar suas decisões, são fluxos de utilidades obtidas a partir da atividade governamental. [...] Diante de diversas alternativas mutuamente exclusivas, um homem racional

\footnotetext{
${ }^{4}$ Define-se por Ação Social de modo racional referente a fins: quanto ao comportamento de objetos do mundo exterior e de outras pessoas, utilizando essas expectativas como "condição" ou "meios" para alcançar fins próprios, ponderados e perseguidos racionalmente, como sucesso (WEBER, 1991 p. 15).
} 
sempre escolhe aquela que Ihe trará a maior utilidade, ceteris paribus, isto é, ele age para seu próprio e maior benefício. (DOWNS, 1999, p. 57).

Para o modelo downsiniano, o comportamento humano é maximizante; mas para o modelo economicista, o comportamento humano é "satisfacionista". (satisfacing behavior) (FIGUEIREDO, 2008, p. 78) No modelo economicista a satisfação do eleitor é relacionada ao aspecto econômico. E o êxito econômico terá reflexos na avaliação do governo.

Em relação à racionalidade econômica, Buchanan e Tullock (2004) apresentam a política como uma esfera na qual o cálculo estratégico que "está em jogo" é o aspecto econômico. Desse modo, os indivíduos racionalmente fazem suas escolhas tendo em vista o benefício econômico que terão com sua ação.

De acordo com Camargo (1999), são duas as principais teorias que abordam a relação entre economia e voto. Na primeira, os cidadãos votam retrospectivamente, de acordo com a sua percepção do desempenho do atual governante na economia. O eleitor decide, como um juiz, se ele deve ou não continuar no governo. Sendo a avaliação positiva, vota no governante; sendo negativa, vota na oposição (KEY, 1966; KRAMER, 1971; FIORINA, 1981). A segunda teoria relacionada ao voto "satisfacionista" é o voto prospectivo, tendo em vista a avaliação do governo atual, o eleitor faz uma projeção futura da continuidade do governo e se considerar que as ações do candidato terão êxito votará pela continuidade, do contrário votará na oposição.

De acordo com Camargo (1999, p. 8), “[...] os dois tipos de voto não são mutuamente excludentes, um eleitor pode agir retrospectivamente e prospectivamente ao mesmo tempo [...]".

Nesse sentido, Fiorina (1981) argumenta que tomar conhecimento sobre as ações do governo é um meio particularmente mais "barato" de chegar à decisão de que eleger, uma vez, para fazê- 
lo, muitas vezes não é preciso na além de estar vivo. Todo cidadão recorrendo ao seu cotidiano e aos problemas encontrados pode saber com facilidade o impacto do governo na economia e nos problemas sociais. Para Fiorena (1981), o voto retrospectivo é um caminho para o voto prospectivo.

Nesse contexto, Key (1966) enfatiza a explicação sobre os limites da racionalidade do eleitor. De acordo com o autor, o eleitor vota de acordo com as informações que estão ao seu alcance, tanto em relação ao aspecto econômico como observando as informações sobre os partidos. Em seu livro "The Responsive Electorate", Key analisou surveys realizados em 1940 e 1960 e comparou as concepções que os eleitores têm sobre economia, as ações de governos passados e sobre a habilidade de cada candidato a presidente no período, com suas intenções de voto e com o seu voto na eleição anterior.

Key foi um dos fundadores de uma teoria sobre a direção do voto, que ainda hoje é debatida por estudiosos, chamada recompensa-punição. Essa teoria baseia-se na premissa de que cada indivíduo age em resposta ao que percebe e experimenta em relação à economia (CAMARGOS, 1999 - grifo do autor).

Kramer que discute o voto econômico segue a mesma linha desenvolvida por Key, segundo a qual os eleitores baseiam-se na avaliação do desempenho passado do candidato situacionista. "Se o desempenho do partido no governo for 'satisfatório' de acordo com algum padrão simples, os eleitores votam para mantê-lo no governo, permitindo que continuem a implementar suas políticas; se o desempenho for considerado 'não-satisfatório' os eleitores votam contra o partido situacionista, dando uma chance à oposição" (KRAMER, 1971, p. 134 apud CAMARGOS, 1999) 
Kiewiet (1983) é outro autor que segue a abordagem econômica, porém destaca a importância de outros fatores além do econômico para a decisão do voto, como questões morais e culturais.

A partir do modelo econômico, Kiewiet (apud CAMARGOS 1999) construiu um modelo de compreensão do voto a partir das duas dimensões econômicas (voto retrospectivo e prospectivo) que deu origem a quatro tipos de interpretações.

De acordo com Camargos (1999), “Os modelos de Kiewiet mostraram que tanto a experiência pessoal como a avaliação da economia nacional agem sobre a decisão de voto retrospectiva e também prospectiva. A combinação dessas dimensões originam quatro tipos de avaliações que são feitas pelos eleitores [...]".

O primeiro tipo de avaliação é o voto Retrospectivo Pessoal quando os eleitores avaliam o desempenho econômico do governo tendo em vista sua experiência pessoal e, por conseguinte, os benefícios pessoais. Já o Retrospectivo Sociotrópico ocorre quando os eleitores que percebem que a situação econômica melhorou tendem a apoiar o candidato que está no poder; enquanto os que consideram que a situação econômica piorou tendem a votar na oposição.

No entanto, no voto Prospectivo Pessoal os eleitores tendem a decidir seu voto de acordo com a prioridade de cada partido, levando em consideração os aspectos pessoais. Para finalizar, o terceiro tipo de voto é o Prospectivo Sociotrópico, que ocorre quando os eleitores votam tendo em vista avaliação que fazem da situação econômica nacional.

Por fim, temos dois exemplos expressivos no nível nacional de pesquisas que utilizaram a teoria da escolha Racional e voto economicista: os trabalhos de Malco Camargos (1999) e Yan de Souza Carreirão (2002) ambos sobre a análise das eleições presidenciais.

Camargos (1999) procurou identificar a influência da economia para a decisão do voto nas eleições presidenciais de 1998. De acordo com o autor (1999), “[...] verificou-se que o impacto das variáveis 
econômicas, de avaliação de governo e de preferência partidária sobre o voto varia de candidato para candidato" (Nesse caso, FHC e Lula). Em relação à tipologia de Kiewiet, o voto retrospectivo/prospectivo sociotrópico tem mais ênfase no Brasil do que o pessoal.

[...] exerce um impacto maior no voto de ambos os candidatos as variáveis de avaliação que o eleitor faz da situação nacional e não as de avaliação da própria situação, sugerindo, com isso, que o eleitor brasileiro é menos preocupado com o próprio bolso do que o eleitor americano (CAMARGOS, 1999).

Carreirão (2002) analisou as eleições presidenciais de 1989, 1994 e 1998 e procurou identificar as determinantes do voto a partir das seguintes variáveis: a imagem política que o eleitor tem dos candidatos e partidos, avaliação de desempenho do governo (presidente), imagem políticas sobre o governo e candidatos e a avaliação que o eleitor faz sobre atributos pessoais dos candidatos envolvidos na disputa.

\section{ELEIÇÃO DE 2008}

Na eleição de 2008 no município de São Paulo, pode-se dizer que a conjuntura estadual era favorável à Kassab, já que o governador José Serra (PSDB), ex-prefeito da capital, o apoiava. Porém, Marta Suplicy esperava que obtivesse um maior percentual de votos devido ao apoio do presidente Lula (PT), que contava com altos índices de aprovação. O apoio de Serra a Kassab não chegava a ser oficial, pois o seu partido tinha como candidato Geraldo Alckmin. No entanto, podemos ver nesta disputa, o efeito "cristianização5", conhecido como a situação em que um partido lança um candidato,

\footnotetext{
${ }^{5}$ Em 1950, Cristiano Machado - político mineiro, sem expressão nacional era representante do PSB, porém os líderes do partido apoiaram oficialmente o candidato, mas, extra-oficialmente apoiaram Getulio Vargas e trabalharam para sua eleição.
} 
mas apóia extra-oficialmente o candidato de outra legenda, tal como aconteceu na disputa das eleições presidenciais em 1950.

A candidata e ex-prefeita Marta Suplicy havia deixado o Ministério de Turismo no governo Lula para disputar o pleito em SP, mas antes de deixar o cargo ficaram notórias suas declarações polêmicas sobre a situação do caos aéreo do país.

Em contrapartida, o candidato à reeleição Gilberto Kassab apresentava uma baixa avaliação de sua administração, começando a campanha com apenas com $32 \%$ de satisfação com a gestão, percentual que cresceu muito no decorrer do primeiro turno e no segundo, o que possibilitou que ele vencesse a eleição.

O mandatário de São Paulo (SP), Gilberto Kassab (Democratas - DEM), iniciou o pleito com apenas 32\% de avaliação positiva de sua gestão e $27 \%$ de rejeição. No decorrer do primeiro turno, que tem duração de 45 dias, fez crescer a aprovação de sua gestão em 14 pontos e reduziu a rejeição em três pontos junto ao eleitorado (VEIGA et al , 2010).

Assim, o cenário eleitoral do primeiro turno teve a disputa delimitada por Gilberto Kassab (DEM), destacando os aspectos positivos de seu governo, como as melhorias realizadas na sua gestão e enfatizava que em dois anos como prefeito havia realizado mais obras do que Marta Suplicy, na administração 2000/2004. Por sua vez, Marta Suplicy procurava destacar os aspectos negativos da gestão Serra/Kassab, destacava os pontos positivos de sua administração enquanto prefeita. Ou seja, Kassab adotou o discurso típico de um mandatário em busca de sua reeleição, enquanto Marta lançou mão de uma retórica pertinente com a sua situação de oposição.

Tabela 1 - Resultado do 1a turno São Paulo, 2008 
v. 8 - n. 2- agosto-dezembro/2011 - ISSN: 1806-5023

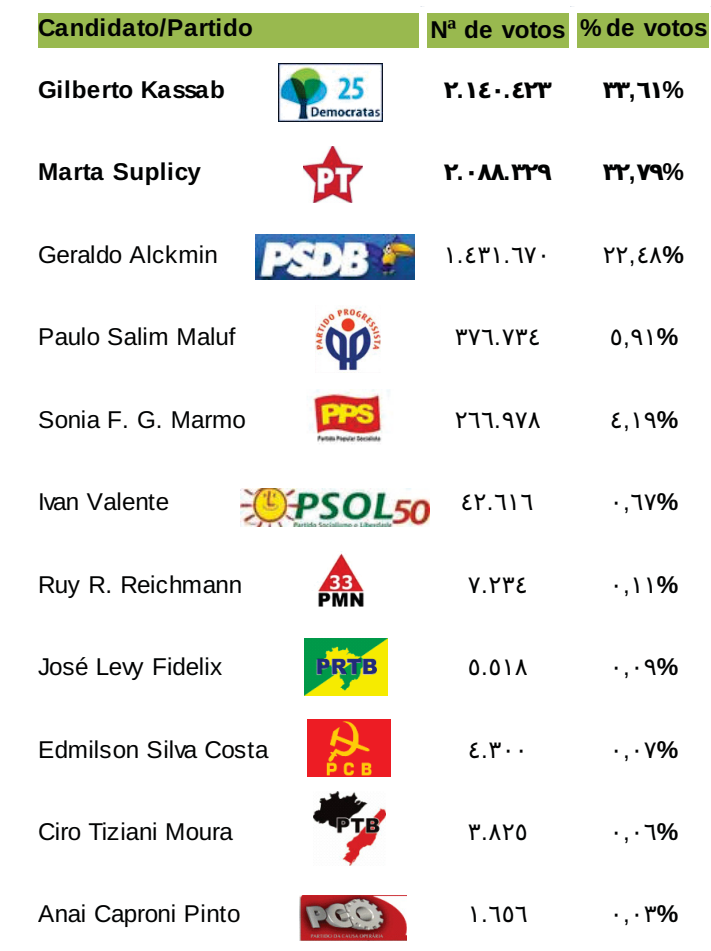

Fonte: TSE (2008)

O resultado do primeiro turno deixou a disputa da administração municipal entre Gilberto Kassab (DEM) e Marta Suplicy (PT). O candidato democrata obteve $33,61 \%$ dos votos $(2.140 .423$ votos), enquanto a petista obteve $32,79 \%$ (2.088.329).

Kassab foi o grande destaque do primeiro turno, pois, no início da campanha eleitoral e nas primeiras pesquisas de opinião estava desacreditado e conseguiu ao longo da campanha desbancar Geraldo Alckim (PSDB), que estava cotado para disputar o segundo turno com Marta Suplicy.

\subsection{VARIÁVEIS SÓCIO - DEMOGRÁFICAS}

De acordo com o alguns apontamentos teóricos, as variáveis sociodemográficas e as variáveis satisfacionistas são apresentadas como preditoras do voto. Sendo assim, no primeiro momento 
apresentaremos o cruzamento entre as variáveis sociodemográficas e a intenção de voto e, posteriormente a relação entre avaliação do governo municipal, estadual e federal junto à intenção de voto. Todas as análises descritivas das tabelas são desenvolvidas com base em análise residual, cujo objetivo é identificar as diferenças significantes entre as categorias das variáveis ${ }^{6}$ e sucedido do teste significância, que visa testar identificar possíveis associações. Para completar, serão apresentados os gráficos referentes análise de correspondência múltipla ou de homogeneidade (HOMALS), visando ilustrar graficamente as relações entre as categorias das variáveis apontadas pelas estatísticas anteriores.

Tabela 2 - Intenção de voto para prefeito, segundo a escolaridade dos eleitores

\begin{tabular}{|c|c|c|c|c|c|c|}
\hline $\begin{array}{c}\text { Intenção } \\
\text { de Voto }\end{array}$ & Analf & $\begin{array}{c}\text { Menos } \\
\text { que } 4^{\mathrm{a}} \\
\text { série }\end{array}$ & $\begin{array}{c}4^{\mathrm{a}} \text { série } \\
\text { completa }\end{array}$ & $\begin{array}{c}8^{\mathrm{a}} \text { série } \\
\text { completa }\end{array}$ & $\begin{array}{c}\text { Ensino } \\
\text { Médio } \\
\text { Completo }\end{array}$ & $\begin{array}{c}\text { Superior } \\
\text { completo }\end{array}$ \\
\hline Kassab & $57 \%$ & $41 \%$ & $32 \%$ & $30 \%$ & $44 \%$ & $70 \%$ \\
\hline Marta & $43 \%$ & $59 \%$ & $68 \%$ & $70 \%$ & $56 \%$ & $30 \%$ \\
\hline
\end{tabular}

Fonte: Banco de dados Ibope - 2008

A relação entre as variáveis escolaridade e intenção de votos para prefeito de São Paulo é apresentada na tabela 1: os eleitores com a 4ạ série, 8ạ série estão mais propensos a votar na Marta, representando $68 \%$ e $80 \%$ das intenções de voto. Enquanto os eleitores com superior completo tendem a optar por Kassab (70\%).

Tabela 3 - Intenção de voto para prefeito, segundo a faixa etária

\footnotetext{
${ }^{6}$ As caselas azuis da tabela representam as diferenças estatísticas em sentido positivo; As caselas laranjas representam as diferenças estatísticas no sentido negativo, conforme a análise residual cujo o valor critério foi 1.96 (positivo, representando as diferenças maiores, e negativas, representando as diferenças menores)
} 


\begin{tabular}{|c|c|c|c|c|c|}
\hline $\begin{array}{c}\text { Intenção } \\
\text { de Voto }\end{array}$ & $\begin{array}{c}16-24 \\
\text { anos }\end{array}$ & $\begin{array}{c}25 \text { a } 34 \\
\text { anos }\end{array}$ & $\begin{array}{c}35 \text { a } 44 \\
\text { anos }\end{array}$ & $\begin{array}{c}45 \text { a } 59 \\
\text { anos }\end{array}$ & $\begin{array}{c}60 \text { anos ou } \\
\text { mais }\end{array}$ \\
\hline Kassab & $27 \%$ & $34 \%$ & $40 \%$ & $43 \%$ & $74 \%$ \\
\hline Marta & $73 \%$ & $66 \%$ & $60 \%$ & $57 \%$ & $26 \%$ \\
\hline
\end{tabular}

Fonte: Banco de dados Ibope - 2008

Quanto à variável faixa etária, os eleitores nas faixas etárias de 16 a 24 anos e 25 a 34 anos mostram uma inclinação nas intenções de voto para Marta Suplicy, representando respectivamente $73 \%$ e $66 \%$ das intenções de voto. Nota-se que conforme aumenta a faixa etária ocorre um declínio nas intenções de voto em Marta Suplicy chegando a $26 \%$ das intenções de voto entre os eleitores na faixa de 60 anos ou mais.

No entanto, os eleitores na faixa etária de 60 anos ou mais demonstram uma propensão a votarem em Kassab, representando $74 \%$ das intenções de voto nessa faixa etária. Essa diferença entre as categorias é representada através dos resíduos padronizados, que demonstram que existe uma diferença estatística entre as categorias de escolaridade.

$\mathrm{Na}$ tabela 4, observa-se a distribuição de votos, segundo a renda dos entrevistados. Eleitores com renda de até 1 salário mínimo mostram uma inclinação à votarem em Marta Suplicy, representando $84 \%$ das intenções de voto, enquanto as intenções de voto de Kassab nesse faixa representam $16 \%$.

Entre as faixas de renda mais elevadas, 5 a 20 salários mínimos e mais de 20 salários mínimos, os eleitores possuem maior inclinação a votar em Gilberto Kassab, representando respectivamente $51 \%$ e $59 \%$ das intenções de voto dessas categorias. No entanto, as intenções de voto de Marta Suplicy têm um declínio nessas faixas de renda, chegando a $33 \%$ das intenções de voto. 
Tabela 4 - Intenção de voto para prefeito, segundo a renda em salário mínimo7

\begin{tabular}{|c|c|c|c|c|}
\hline $\begin{array}{c}\text { Intenção } \\
\text { de Voto }\end{array}$ & $\begin{array}{c}\text { Até } 1 \\
\text { SM }\end{array}$ & $\begin{array}{c}\text { Mais de } \\
1 \text { até } 5 \\
\text { SM }\end{array}$ & $\begin{array}{c}\text { Mais de } \\
5 \text { a } 20 \\
\text { SM }\end{array}$ & $\begin{array}{c}\text { Mais de } \\
20 \text { SM }\end{array}$ \\
\hline Kassab & $16 \%$ & $39 \%$ & $51 \%$ & $59 \%$ \\
\hline Marta & $84 \%$ & $61 \%$ & $49 \%$ & $41 \%$ \\
\hline
\end{tabular}

Fonte: Banco de dados Ibope - 2008

A intenção de voto, em relação às variáveis renda e escolaridade, segue a mesma dinâmica do voto observada por Carreirão (2008) na eleição presidencial de 2006. Eleitores com renda baixa e menos escolarizados tendem a votar nas opções de esquerda.

Tabela 5 - Intenção de voto pra prefeito, segundo o sexo

\begin{tabular}{|c|c|c|}
\hline $\begin{array}{c}\text { Intenção } \\
\text { de Voto }\end{array}$ & \multicolumn{2}{|c|}{ Sexo } \\
\hline Kassab & $37 \%$ & Fem \\
\hline Marta & $63 \%$ & $58 \%$ \\
\hline
\end{tabular}

Fonte: Banco de dados Ibope - 2008

Em relação a variável sexo, é possível afirmar que os homens se mostram mais propensos a votarem em Marta Suplicy, sendo que $63 \%$ intencionaram votos à candidata contra $37 \%$ para o Kassab. Entre as mulheres, a inclinação também é pró Marta, 58\% tendem a optar pela candidata, enquanto os outros $44 \%$ tendem a votar em Kassab.

Para concluir a análise das variáveis sociodemográficas, apresentamos o gráfico das bases sociais das intenções de voto. Para ${ }^{7}$ O valor do salário mínimo em 2008 era R\$ 415,00. 
melhor visualização dos dados e das relações estabelecidas entre as categorias, foi realizada uma análise de correspondência múltipla ou de homogeneidade (HOMALS), que dispõe os dados das variáveis em um plano gráfico. Esse é um tipo de análise multivariada que reduz as dimensões dos dados de uma matriz de duas ou mais entradas, sendo possível analisar virtuais correspondências entre as categorias dessas variáveis, ou seja, a relação que as categorias estabelecem conjuntamente e simultaneamente em um plano gráfico bidimensional simples $^{8}$, cada ponto do gráfico 1 é referente a uma categoria das variáveis dispostas na legenda. O destaque em vermelho apresenta um panorama das intenções de voto de Marta Suplicy e em azul, as intenções de voto de Kassab.

\section{Gráfico 1 - Bases sociais dos candidatos Marta e Kassab}

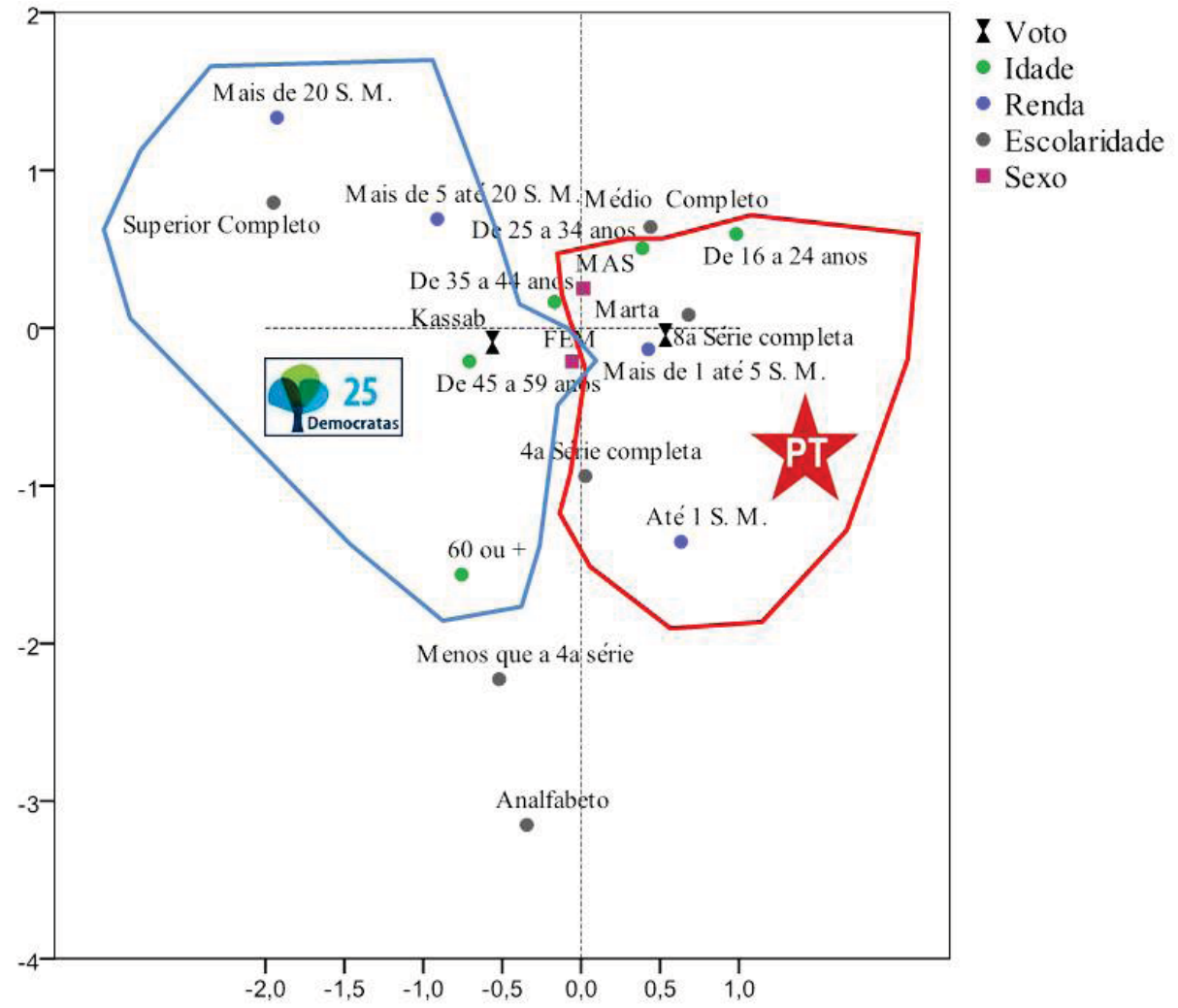

\footnotetext{
${ }^{8}$ A HOMALS tem correspondência direta com o teste de associação entre variáveis, o Qui-Quadrado
} (MINGOTI, 2005, p. 266). 
De acordo com o gráfico, eleitores que se encontram na faixa etária de 16 a 24 anos e de 35 a 44 anos, que possuem escolaridade entre $5^{\underline{a}}$ até a $8^{a}$ série e ensino médio incompleto e renda de até 5 salários mínimos tendem a votar em Marta Suplicy (PT). Enquanto eleitores nas faixas etárias de 45 a 59 anos e mais 60 anos, de ensino superior completo e que estão situados nas faixas de renda entre mais de 5 a 20 salários mínimos e mais de 20 salários mínimos tem uma propensão maior a votarem em Gilberto Kassab (DEM).

Com as variáveis satisfacionistas seguiremos o mesmo processo adotado para análise das variáveis sócio-demográficas: apresentaremos o cruzamento entre as variáveis, seguido da análise de resíduos nas variáveis avaliação da administração municipal, estadual e federal. Para complementar a análise, tem-se a correspondência múltipla ou de homogeneidade (HOMALS), que sintetizará os dados obtidos através dos testes.

Observando a tabela 6 é possível constatar que os eleitores que avaliam negativamente a administração de Gilberto Kassab (DEM), como péssima, ruim e regular representam respectivamente, 97\%, $91 \%$ e $74 \%$ das intenções de voto. Essas categorias de eleitores se apresentam mais propensos a votar na candidata da oposição, Marta Suplicy (PT).

Há uma tendência de que os eleitores que avaliam a administração de Kassab como positiva, soma de boa e ótima, (59\% e $80 \%$ respectivamente) votem na reeleição de Kassab. Nesse sentido, quanto maior a aprovação da administração de Gilberto Kassab menor é o percentual de intenções de voto em Marta Suplicy.

Tabela 6 - Intenção de voto para prefeito, segundo a avaliação da administração municipal 
v. 8 - n. 2- agosto-dezembro/2011 - ISSN: 1806-5023

\begin{tabular}{|c|c|c|c|c|c|}
\hline $\begin{array}{r}\text { Intenção } \\
\text { de voto }\end{array}$ & Péssimo & Ruim & Regular & Bom & Ótimo \\
\hline Kassab & $3 \%$ & $10 \%$ & $26 \%$ & $59 \%$ & $80 \%$ \\
\hline Marta & $97 \%$ & $90 \%$ & $74 \%$ & $41 \%$ & $20 \%$ \\
\hline
\end{tabular}

Fonte: Banco de dados Ibope - 2008

Dessa forma reforça-se a premissa de que os eleitores que avaliam a administração positivamente tendem a reeleger 0 candidato, nesse caso Gilberto Kassab (DEM). A partir desses dados, podemos supor que a avaliação que o eleitor faz do governo influencia seu voto na próxima eleição.

Em relação à avaliação da administração estadual, a tabela 7 demonstra que existe uma relação entre a aprovação da administração estadual e as intenções de voto para prefeito. Nota-se que entre os eleitores que avaliam a administração estadual como positiva: $54 \%$ boa e $60 \%$ ótima, há uma tendência de votos em Gilberto Kassab.

De acordo com Anastasia (2009): “O DEM conquista a vitória na cidade de São Paulo, onde a candidatura do partido foi apoiada pelo governador do Estado, José Serra, contra um candidato do próprio partido do governador, o PSDB".

No entanto, percebe-se que entre os eleitores que avaliaram a administração estadual como péssima, ruim e regular existe uma tendência de que estes eleitores votem em Marta Suplicy, representando respectivamente, $78 \%, 74 \%$ e $65 \%$ das intenções de voto.

Tabela 7 - Intenção de voto para prefeito, segundo a avaliação da administração estadual 
v. 8 - n. 2- agosto-dezembro/2011 - ISSN: 1806-5023

\begin{tabular}{|c|c|c|c|c|c|}
$\begin{array}{c}\text { Intenção } \\
\text { de Voto }\end{array}$ & Péssimo & Ruim & Regular & Bom & Ótimo \\
\hline Kassab & $22 \%$ & $26 \%$ & $35 \%$ & $54 \%$ & $60 \%$ \\
\hline Marta & $78 \%$ & $74 \%$ & $65 \%$ & $46 \%$ & $40 \%$ \\
\hline
\end{tabular}

Por fim, a tabela 8 indica a associação existente entre a intenção de voto e avaliação da administração federal, do presidente Lula. Através dos dados é possível perceber que entre os eleitores que avaliam a administração federal como boa e ótima, existe uma tendência de que votem em Marta Suplicy (PT), representando respectivamente, $66 \%$ e $80 \%$ das intenções de voto. Nesse caso, é possível perceber que a avaliação do governo federal é uma variável impactante para a intenção de votos em Marta.

Tabela 8 - Intenção de voto para prefeito, segundo a avaliação da administração federal

\begin{tabular}{|c|c|c|c|c|c|}
$\begin{array}{c}\text { Intenção } \\
\text { de Voto }\end{array}$ & Péssimo & Ruim & Regular & Bom & Ótimo \\
\hline Kassab & $66 \%$ & $61 \%$ & $58 \%$ & $34 \%$ & $20 \%$ \\
\hline Marta & $34 \%$ & $39 \%$ & $42 \%$ & $66 \%$ & $80 \%$ \\
\hline
\end{tabular}

Os eleitores que avaliam a administração federal como péssima e ruim mostram-se propensos a votarem em Gilberto Kassab (DEM), $66 \%$ e $61 \%$ respectivamente. Dessa forma, é possível perceber que entre as variáveis satisfacionistas, a avaliação da administração municipal e federal são as que representam maior impacto nas intenções de voto. 
Os dados indicam que a avaliação da administração da esfera federal tem impacto nas eleições municipais e que o eleitor que fez essa avaliação positiva tendeu a votar no candidato que tem o apoio do governo federal, nesse caso Marta Suplicy (PT).

Por fim, apresentamos a análise de homogeneidade (HOMALS) que é síntese das análises acima, apresentadas no gráfico 2 .

De acordo com os dados dispostos no gráfico, os eleitores que avaliam a administração municipal e estadual positivamente, entre boa e ótima - e como insatisfatória a avaliação da administração federal tende a votar em Gilberto Kassab (DEM). Contrariamente, eleitores que avaliaram negativamente a administração municipal e estadual e que aprovam a administração federal tendem a votar em Marta Suplicy (PT)

Gráfico 2 - Bases satisfacionistas dos candidatos Marta e Kassab 


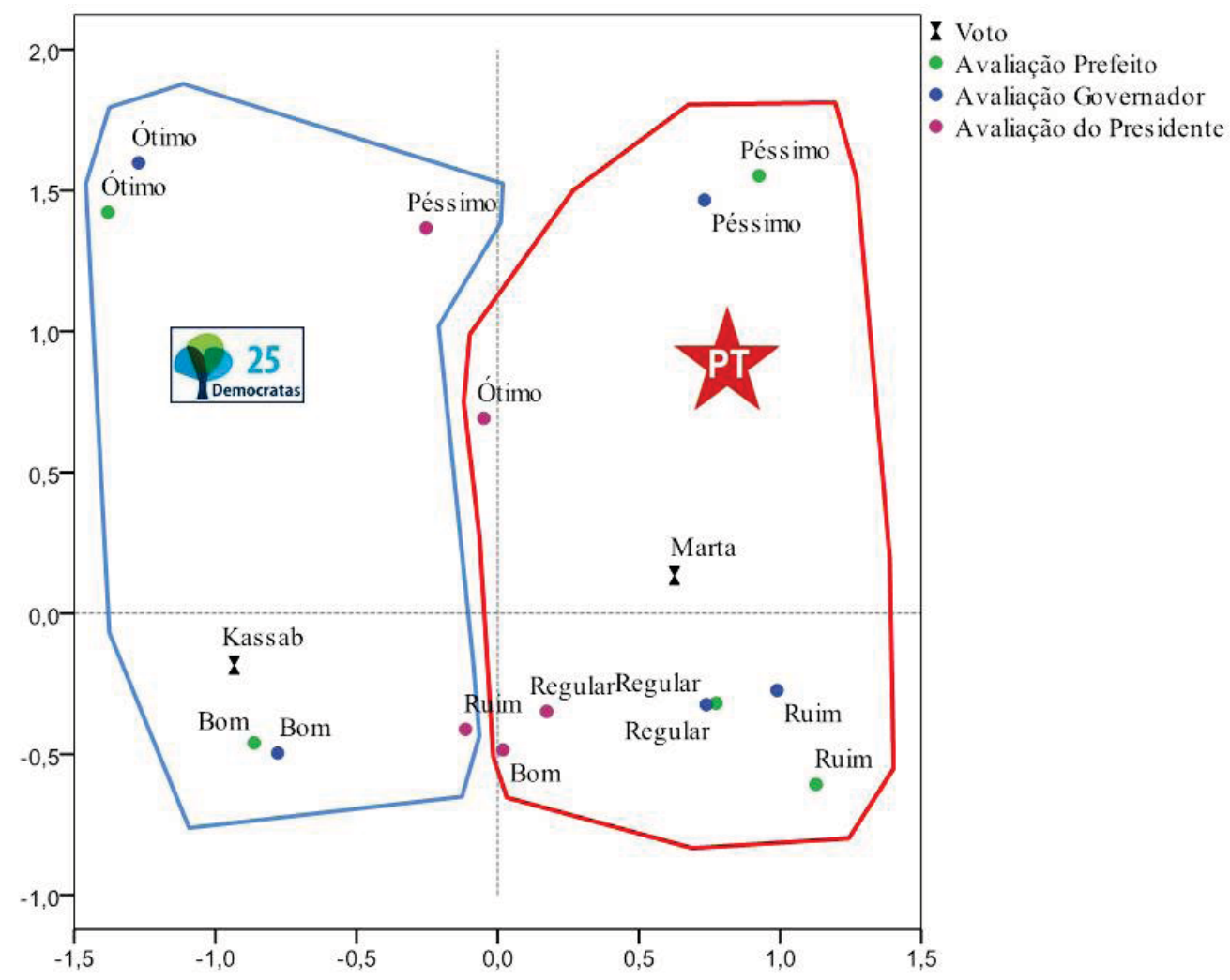

Após a apresentação do contexto da eleição de 2008, o cruzamento entre as variáveis e análise residual entre os dois grupos de variáveis, visando aprofundar a análise sobre o tema, apresentamos os testes de regressão.

Para melhor compreensão sobre o impacto das variáveis na intenção de voto pra prefeito, fez-se uma análise preditiva multivariada (regressão logística). Optou-se por tal teste estatístico, devido à "maior exatidão" que o teste proporciona, sendo que uma das exigências do teste é que a variável dependente seja obrigatoriamente dummy ou binária (que expressa ausência ou presença de um atributo), e que as variáveis explicativas sejam binárias ou escalares.

Foi gerado um modelo de regressão logística para as variáveis sociodemográficas, porém, as significâncias do modelo e das variáveis não permitiram dar sequência às análises. No entanto, o segundo grupo de variáveis, as satisfacionistas se mostraram significativas. As 
variáveis foram divididas em duas tabelas. A tabela 9 apresenta como presença de atributo o voto em Gilberto Kassab, e a 10 em Marta.

Tabela 9 - Votos em Kassab

\begin{tabular}{|c|c|c|c|c|c|}
\hline Variáveis & B & Wald & Sig. & Exp(B) & $\begin{array}{c}\text { Razão de } \\
\text { Chance }\end{array}$ \\
\hline $\begin{array}{c}\text { Avaliação do } \\
\text { Prefeito }\end{array}$ & 1.195 & 125.104 & .000 & 3.304 & $234 \%$ \\
\hline $\begin{array}{c}\text { Avaliação do } \\
\text { Governador }\end{array}$ & -.066 & .746 & .388 & .936 & \\
\hline $\begin{array}{c}\text { Avaliação do } \\
\text { Presidente }\end{array}$ & -.248 & 15.786 & .000 & .780 & $-22 \%$ \\
\hline Constant & -4.225 & 91.129 & .000 & .015 & \\
\hline
\end{tabular}

A primeira variável do modelo é a satisfação com a administração do prefeito, segundo o resultado do teste, a medida em que o eleitor aumenta uma unidade na avaliação do prefeito, aumenta $234 \%$ as chances do eleitor votar pela reeleição de Kassab. Em relação à avaliação do presidente, o aumento de uma unidade em sua avaliação, significa uma redução de $22 \%$ nas chances de votar em Kassab.

Tabela 10 - Votos em Marta

\begin{tabular}{|c|c|c|c|c|c|}
\hline Variáveis & $\mathrm{B}$ & Wald & Sig. & Exp(B) & $\begin{array}{c}\text { Razão de } \\
\text { Chance }\end{array}$ \\
\hline $\begin{array}{c}\text { Avaliação do } \\
\text { Prefeito }\end{array}$ & -.516 & 52.433 & .000 & .597 & $-40 \%$ \\
\hline $\begin{array}{c}\text { Avaliação do } \\
\text { Governador }\end{array}$ & -.337 & 23.567 & .000 & .714 & $-29 \%$ \\
\hline $\begin{array}{c}\text { Avaliação do } \\
\text { Presidente }\end{array}$ & .739 & 105.306 & .000 & 2.094 & $109 \%$ \\
\hline Constant & -.480 & 2.181 & .140 & .619 & \\
\hline & $\mathrm{N}=1086$; Sig. & .000; $\mathrm{R}^{2}$ (Nagelkerke) $=.261$ & \\
\hline
\end{tabular}


A tabela 2 apresenta o modelo com o voto na candidata Marta Suplicy. Em relação à administração do prefeito Kassab, é possível perceber que na medida em que o indivíduos aumentam uma unidade na avaliação para o prefeito, diminuem $40 \%$ as chances do eleitor votar em Marta Suplicy. Em relação à avaliação do governador, na medida em que o eleitor aumenta uma unidade da avaliação do mesmo, diminuem $29 \%$ as chances de o eleitor votar na candidata. Por fim, a avaliação do presidente, demonstra que na medida em que o eleitor aumenta uma unidade na avaliação do presidente, aumentam $109 \%$ as chances de o eleitor votar em Marta Suplicy.

\section{CONSIDERAÇÕES FINAIS}

No decorrer deste trabalho procuramos analisar o impacto das variáveis sociodemográficas e das variáveis satisfacionistas na intenção de voto para prefeito de São Paulo em 2008, relacionando as intenções de voto de Marta Suplicy (PT) e de Gilberto Kassab (DEM).

Entre as variáveis sócio-demográficas, a variável sexo do eleitor (gênero) foi a que demonstrou menor associação com a intenção de voto. Esse é um aspecto que também é observado nas análises das eleições presidenciais (CARREIRÃO, 2008). As demais variáveis: escolaridade, faixa etária e renda demonstraram maior significância explicativa na identificação das intenções de voto entre os dois candidatos em questão.

Quanto à escolaridade, a tendência é que eleitores de $5^{\underline{a}}$ a 8$^{a}$ série e ensino médio incompleto estivessem propensos a votarem na candidata petista, Marta Suplicy. Enquanto os eleitores que possuem escolaridade mais elevada votem no democrata Gilberto Kassab.

Em relação à faixa etária, observou-se uma tendência de que os eleitores mais jovens estejam propensos a votarem em Marta Suplicy. Sendo que os eleitores situados nas faixas etárias mais elevadas demonstrem a intenção de votar em Kassab. 
Quanto à associação entre renda e intenção de voto, eleitores que possuem renda de até 1 salário mínimo mostram-se propensos a votarem em Marta Suplicy, enquanto os eleitores que possuem renda nas faixas mais altas, acima de 5 salários mínimos tendem a votarem em Gilberto Kassab.

Em relação ao segundo grupo de variáveis, as satisfacionistas, as três categorias - administração municipal, estadual e federal foram relevantes para a intenção de voto a prefeito municipal. Esse fato é comprovado teoricamente por meio dos trabalhos de Anastasia (2009), Almeida (2008) e Veiga et al (2010). Esses autores apresentaram em seus trabalhos a ideia que existe uma relação acentuada entre a satisfação da população com o governo federal e as eleições municipais.

Almeida (2008) argumenta no sentido de que o eleitor segue uma ideia lógica para a decisão do voto e, nesse raciocínio, a avaliação do governo é um dos fatores preditores do voto.

Os eleitores que avaliaram positivamente governo federal têm a propensão a votarem na candidata petista. Sendo assim, pode-se dizer que a avaliação positiva do governo Lula teve impacto nas intenções de votos em Marta Suplicy. Para Anastasia (2009), os partidos apoiados pelo governo federal conseguiram angariar a popularidade do governo federal e reverter o apoio do governo em votos.

Em relação às demais variáveis - avaliação da administração estadual e da municipal - eleitores que avaliam positivamente a gestão de José Serra (PSDB) tendem a votar em Gilberto Kassab (DEM), candidato de direita. Nesse sentido, nota-se a importância das coligações partidárias e das composições das forças de oposição como determinante para as eleições municipais (ANASTASIA, 2009).

Em relação às eleições municipais de 2008, ANASTÁSIA (2009) sugere que a satisfação dos eleitores com a administração federal possa ter sido revertida em votos para os candidatos apoiados pelo governo federal. 


\section{REFERÊNCIAS}

ANASTASIA, Fátima. Brasil, Dos décadas de democracia. Revista de Ciencia Política, vol.29, $\mathrm{n} \cong 2$, Santiago, 2009. p. 275 - 300.

CAMARGOS, Malco. Do bolso às urnas - $A$ influência da economia na escolha entre Fernando Henrique e Lula nas eleições de 1998. Dissertação (mestrado), IUPERJ, Rio de Janeiro, 1999.

CARREIRÃO, Yan S. A decisão do voto do eleitor catarinense (19982006). Civitas, Porto Alegre, n. 2. p. 207-236, 2008.

CASTRO, Mônica M M. Determinantes do Comportamento Eleitoral: a centralidade da Sofisticação Política. Tese de Doutorado, IUPERJ, Rio de Janeiro, 1994.

Sujeito e Estrutura no Comportamento Eleitoral. Revista Brasileira de Ciências Sociais. N 20, 1992.

DOWNS, Anthony. Uma teoria econômica da democracia. São Paulo: EDUSP: 1999.

FIGUEIREDO, Marcus. A decisão do voto: democracia e racionalidade. 2aㅡ. Ed. Belo Horizonte: UFMG, 2008.

FIORENA, Morris P. Retrospective Voting in American National Election. New Haven e Londres, Yale University Press, 1981.

LAMOUNIER, Bolívar; CARDOSO,Fernando $\mathrm{H}$ (org). Os partidos e as eleições no Brasil. Rio de Janeiro: Paz e Terra, 1978.

LAZARSFELD, P. F.; BERELSON, B. e GAUDET, H. The peoples's choice: how the voter makes up his mind in a presidential campaign. $3^{\text {a }}$ ed. New York: Columbia University Press, 1969 [1944].

LIPSET, Seymour M. O homem político. Rio de Janeiro: Zahar, 1967.

MINGOTI, Sueli Aparecida. Análise de dados através de métodos de estatística multivariada: uma abordagem aplicada. Belo Horizonte, Editora UFMG, 2005.

VEIGA, Luciana Fernandes; NEVES, Daniela; SANTOS, Sandra Avi. Prefeito bem avaliado, prefeito reeleito? Sobre o peso da satisfação 
com a administração na eleição. Anais do 70 Encontro da ABCP, Recife - PE, 2010.

TELLES, Helcimara Souza. O eleitor e a lógica do voto: a (des)articulação entre o local e o nacional. Anais do 70 Encontro da ABCP, Recife - PE, agosto de 2010.

TSE - TRIBUNAL SUPERIOR ELEITORAL. Estatística TSE - Eleições 2008. Disponível em:

<http://www.tse.jus.br/internet/eleicoes/estatistica2008 Lest_result/resultadoEleicao.htm>. 


\section{RESUMO}

O objetivo deste artigo é identificar o impacto das variáveis sociodemográficas (grau de escolaridade, renda familiar, idade e sexo) e das variáveis satisfacionistas (avaliação municipal, estadual e federal) para a decisão do voto na eleição para a Prefeitura de São Paulo em 2008 a partir do banco de dados do Instituto Brasileiro de Opinião Pública e Estatística - IBOPE. A hipótese do trabalho é que eleitores de baixa renda e escolaridade estavam mais propensos a votarem na candidata Marta Suplicy. E em relação às variáveis satisfacionistas, a hipótese é que a satisfação com a administração interfere na intenção de voto.

PALAVRAS-CHAVE: eleições municipais; comportamento eleitoral; voto

\section{ABSTRACT:}

The aim of this paper is to identify the impact of sociodemographic variables (education, family income, age and sex) and satisfaction of voters (evaluation of government) to the voting decision in the election of São Paulo in 2008 based on the database of the Brazilian Institute of Public Opinion and Statistics -IBOPE. The hypothesis is that satisfaction with the administration interferes with the intention to vote for Marta Suplicy. As far as satisfaction variables are concerned, the hypotesis is that satisfaction with the administration interferes with the vote intention.

KEYWORDS: election of São Paulo; electoral behavior; vote. 